\title{
Body Composition Analysis by Dual-Energy X-Ray Absorptiometry in Women Aged 20-75 Years
}

\author{
Mihail A Boyanov* \\ Department Internal Medicine, Medical University of Sofia, Bulgaria
}

Submission: April 05, 2017; Published: May 30, 2017

*Corresponding author: Mihail A Boyanov, Professor, Clinic of Endocrinology and Metabolic Diseases, University Hospital Alexandrovska, Department Internal Medicine, Faculty of Medicine, Medical University Sofia, 1, G. Sofiyski street, 1431 Sofia, Bulgaria, Tel: + 3592-9230-784; Fax: + 3592-9230-779; Email: mihailboyanov@yahoo.com

Abstract

Purpose: To measure the total and regional fat and lean mass (FM and LM) in women of different age and to build an age-adjusted dataset using Dual X-ray absorptiometry (DXA).

Methods: This is a retrospective post hoc analysis of a whole body DXA study. 140 women (aged 20-75 years) referred for DXA were eligible. They were subdivided in age groups: 20-44 years (30 premenopausal women), 45-59 years (80 postmenopausal women), and 60-75 years (30 women). DXA was performed on a Hologic QDR 4500 A bone densitometer (Hologic Inc., Bedford MA) with software version 8.26:3. Total body and regional BMC, FM and LM were measured. Regional analysis included arms and legs (the sum of left and right), and the trunk. Statistical analysis was performed by IBM SPSS Statistics 19.0 for Windows.

Results: Comparing the 45-59 versus the 20-44 year-aged groups, FM and LM showed a parallel decrease, while in the elderly group (60-75 years), the decrease of FM was greater than that of LM. The body fat percentage was lowest in the oldest (39.6 6.2 ) and highest in the middleaged group (41.8 \pm 5.8 ), $p=0.04$. Comparing the $45-59$ versus the 20-44 year-aged group, FM and LM showed a parallel decrease in the legs, while in the arms and trunk, FM showed a greater age-related decrease than LM.

Conclusion: Aging has a more pronounced effect on FM than LM. The reduction of both body compartments is different according to the region studied. BMI-adjusted data on body composition in different populations are needed.

Keywords: DXA; Whole body; Regional analysis; Fat mass; Lean mass

List of abbreviations: ALM: Appendicular Lean Mass; BMI: Body Mass Index; DXA: Dual-Energy X-Ray Absorptiometry; FM: Fat Mass; \% FM: Percentage of Fat Mass; LM: Lean Mass

\section{Introduction}

Obesity has become a worldwide epidemic [1]. Its consequences include severely increased morbidity and mortality, as well as impaired quality of life. According to recent publications, $38.8 \%$ of the men and $28.3 \%$ of the women in a random Bulgarian population (1046 women and 912 men) have overweight and obesity [2]. Common measures of overweight and obesity are the body weight, body mass index (BMI), waist circumference, waist-to-hip ratio and some others. They show, however, a number of limitations in differentiating visceral from subcutaneous fat accumulation and increases in lean mass (LM) from those in fat mass (FM).
Body composition analysis provides useful information in epidemiological studies of obesity and overweight, as well as of sarcopenia and frailty [3-5]."Gold standards" for body composition analysis are computed tomography (CT), magnetic resonance imaging (MRI), hydro-densitometry, deuterium oxide dilution techniques and air displacement plethismography, but they are expensive and rather sophisticated for everyday use. Dual-energy X-ray absorptiometry (DXA) is a reliable method for body composition analysis,combining both simplicity of use and objectivity in measuring physically the different body compartments [6,7]. It can also provide precise regional data for different body parts and regions. 
The International Society for Clinical Densitometry (ISCD) 2013 Conference advocated the use of whole body scans and total body composition with regional analysis particularlyin three situations: 1 /in obese patients undergoing bariatric surgery (or medical, diet or weight loss regimens with significant weight loss); 2/in patients with muscle weakness or poor physical functioning (to improve the diagnosis of sarcopenia); and 3 / in HIV patients onanti-retroviral therapy, to assess fat distribution and possible lipoatrophy [8]. An emerging trend is the use of DXA for the estimation of total and appendicular lean mass (ALM) in the setting of sarcopenia $[9,10]$. However, the interpretation of body compartment estimates necessitates some reference values. A number of studies have published data from various reference populations- Europeans, Asians and Americans [1120]. The DXA manufacturers incorporate different reference databases, primarily for bone mineral density and content (BMD and BMC). The NHANES 1999-2004 database is an effort to provide reliable and internationally validated reference values for several indices in the body composition analysis $[11,21]$. The ISCD 2013 Conference recommends using them instead of manufacturer-provided reference populations [22]. Three European organizations (ESCEO/IOF, ESPEN and EUGMS) issued an appeal for local data on body composition to be included in an International Sarcopenia Cohort Study (ISCS).

The aim of the present study was to perform whole body and regional body composition analysis in women aged 20-75 years and to establish age-adjusted data for FM and LM and the percentage of fat mass (\% FM).

\section{Material and Methods}

\section{Subjects}

This is a retrospective post hoc analysis of data coming from a cross-sectional observational study, performed in a hospitalbased outpatient DXA setting. The primary goal of the study was to explore the agreement between the body composition analysis by leg-to-leg BIA and by fan-beam DXA, with the assumption that severe obesity might negatively affect the agreement between the two techniques. The results of the primary analysis have been published elsewhere [23]. A total of 159 women (mean age $49.1 \pm 10.0$ years) were involved in the original study, but after reviewing the available data, only 140 subjects were found suitable for proper analysis of regional body composition. Bearing in mind that several body composition indices reach their peak after the age of 40 years, the subjects were assigned into three groups: 30 women aged 20-44 years, 80 women aged 45-59 years and 30 women aged 60-75 years [21]. The subjects came from an urban background. Seventy two (72) of them were referred for bone density testing (65 postmenopausal and 7 premenopausal women), 56 were referred for body composition analysis because of overweight or obesity (22 premenopausal and 34 postmenopausal women) and 12 were healthy volunteers (1 premenopausal and 11 postmenopausal women).
All women had given their informed consents prior to any procedure. The study was approved by the responsible ethic authorities at the University Hospital and was performed in accordance with the ethical standards as laid down in the Helsinki Declaration (1964) and its later amendments. The inclusion criteria were the patient's informed consent and the availability of readable total and regional body composition data from DXA. Subjects with any medical conditions or medications, known to cause excessive obesity, dehydration and water retention or electrolyte disturbance affecting the body composition measurements, had been excluded from this study. The exclusion criteria included also the presence of multiple deformed or fractured lumbar vertebrae, severe scoliosis $\left(>15^{\circ}\right)$ and other conditions, which might interfere the proper analysis of BMD scans.

Age (in yrs), height (in cm, measured on a Harpender stadiometer), weight (in $\mathrm{kg}$, measured on a standard weight balance) and age at menopause (if menopausal), were recorded prior to the whole body DXA scans. Body mass index (BMI) was calculated from weight and height in $\mathrm{kg} / \mathrm{m}^{2}$.

\section{Body composition analysis}

The whole body DXA was performed in the early morning after an overnight fasting for at least 12 hours. The subjects were required to adhere to standard body composition testing guidelines, wearing light clothes [24]. They were positioned lying supine with the entire body, including all soft tissues, within the table margins. The arms were positioned palm down with a space straight at the patient's sides; the legs were kept together with the feet relaxed. Fan-beam dual-energy X-ray (DXA) body composition analysis was performed on a Hologic QDR 4500 A bone densitometer (Hologic Inc., Bedford, MA 02154, USA). All DXA scans were read by the same technologist in a semiautomatic way, including manual modifications of the regions of interest. The software (version 8.26:3) assumed that brain fat represented $17 \%$ of the body fat. Body composition data were presented by the software as FM in grams, LM in grams, and bone mineral content (BMC) in grams. The percentage of FM (\% FM) was also calculated. Data were calculated separately for the different body sub-regions (arms, legs and trunk), as well as total values according to the ISCD 2013 guideline [8].

\section{Precision study}

The manufacturer-provided standard Hologic tissue bar was scanned once weekly for whole body quality control. The in vivo coefficient of variation ( $\mathrm{CV} \%$ ) of the whole body DXA was calculated from duplicate measurements in 30 female subjects according to Glüer et al. (CV\% = root-mean-squares/mean x 100) [25]. These subjects were randomly selected from the female study population. All retests were performed on the same day within a very short time. The in vivo CV $\%$ of DXA was $0.79 \%$ for \% FM, 760 grams for FM (corresponding to 2.05\%), 710 grams 
for LM (1.46\%), and 40 grams for BMC (2.01\%), which is within the limits advocated by the ISCD 2013 conference [24].

\section{Statistical analysis}

An IBM SPSS 19.0 for WINDOWS package (Chicago, IL, USA) was used for processing the numerical data. The KolmogorovSmirnov test for normal distribution was first performed, followed by tests for homogeneity of variance, and t-tests. Statistical significance was set at $\mathrm{p}$ 20.05. Whole body BMD T-scores were calculated by the software and were expressed in units of SD's above or below the mean of the manufacturerprovided healthy reference for adult pre-menopausal population aged 20-29 years (PS reference data base issued 25 Oct 1991).

\section{Results}

The anthropometric and whole body composition data ofthe subjectsare presented in Table 1. Total body FM was highest in the youngest age-group, with a steeper decline in the elderly group. Total body LM, on the contrary, showed a more pronounced difference between the 20-44 and 45-59 year aged groups than between the 45-59 and 60-75-year aged groups. This discrepancy between the lean and fat mass led to \% FM that was highest in the middle-aged group (45-59 years). Total BMC and BMD declined with advancing age and the intergroup difference was highest in the elderly- 45-59 versus 60-75-year aged group.

Table 1: Anthropometric and body composition data of the study population are shown as means (standard deviations). Total bone mineral content (BMC) as well as LM and FM are presented in kilograms, bone mineral density (BMD) in grams per centimeters squared.

a. $p<0.05$ when compared to the previous age group.

b. According to the manufacturer-provided PS reference data base issued 25 Oct 1991.

\begin{tabular}{|c|c|c|c|c|}
\hline & $\begin{array}{l}\text { Total study } \\
\text { group } \\
(\mathrm{n}=140)\end{array}$ & $\begin{array}{c}20-44 y r s \\
(n=30)\end{array}$ & $\begin{array}{c}\text { 45-59yrs } \\
(n=80)\end{array}$ & $\begin{array}{c}\text { 60-75yrs } \\
(n=30)\end{array}$ \\
\hline Age (yrs) & $51.9(10.0)$ & $35.6(7.4)$ & $52.2(3.3)$ & $66.1(4.9)$ \\
\hline $\begin{array}{c}\text { Age at } \\
\text { menopause } \\
\text { (yrs) }\end{array}$ & $45.8(7.2)$ & NA & $46.5(5.3)$ & 44.0 (11.9) \\
\hline Height $(\mathrm{cm})$ & $161.4(6.0)$ & $161.5(6.4)$ & $161.9(6.0)$ & $\begin{array}{c}160.1(5.6) \\
\mathrm{a}\end{array}$ \\
\hline $\begin{array}{c}\text { Measured } \\
\text { weight }(\mathrm{kg})\end{array}$ & $\begin{array}{c}87.22 \\
(18.62) \\
\end{array}$ & $\begin{array}{c}93.92 \\
(19.60) \\
\end{array}$ & $\begin{array}{c}87.86 \\
(19.18) \mathrm{a} \\
\end{array}$ & $\begin{array}{c}78.36 \\
(11.43) \mathrm{a} \\
\end{array}$ \\
\hline $\begin{array}{l}\text { DXA weight } \\
(\mathrm{kg})\end{array}$ & $\begin{array}{c}87.65 \\
(19.47)\end{array}$ & $\begin{array}{c}94.33 \\
(21.32)\end{array}$ & $\begin{array}{c}88.36 \\
(19.95) a\end{array}$ & $\begin{array}{c}78.62 \\
(11.84) a\end{array}$ \\
\hline $\begin{array}{l}\text { BMI (kg/ } \\
\text { m2) }\end{array}$ & $33.5(7.2)$ & $36.0(8.3)$ & $33.5(7.6) a$ & $30.6(6.3) \mathrm{a}$ \\
\hline $\begin{array}{l}\text { Total FM } \\
\text { (kg) }\end{array}$ & $\begin{array}{c}37.03 \\
(12.91)\end{array}$ & $\begin{array}{c}39.66 \\
(14.88)\end{array}$ & $\begin{array}{c}37.84 \\
(13.21)\end{array}$ & $\begin{array}{c}31.44 \\
(7.66) \mathrm{a}\end{array}$ \\
\hline $\begin{array}{l}\text { Total LM } \\
\text { (kg) }\end{array}$ & $\begin{array}{l}48.60 \\
(7.79)\end{array}$ & $\begin{array}{l}52.48 \\
(8.46)\end{array}$ & $\begin{array}{c}48.49 \\
(7.61) \mathrm{a}\end{array}$ & $\begin{array}{c}45.34 \\
(6.43) \mathrm{a}\end{array}$ \\
\hline $\begin{array}{c}\% \text { Body fat } \\
\text { (\%) }\end{array}$ & $41.2(6.3)$ & 40.7 (8.3) & $41.8(5.8)$ & $39.6(6.2) \mathrm{a}$ \\
\hline
\end{tabular}

\begin{tabular}{|c|c|c|c|c|}
\hline $\begin{array}{c}\text { Total BMC } \\
(\mathrm{kg})\end{array}$ & $\begin{array}{c}2.010 \\
(0.351)\end{array}$ & $\begin{array}{c}2.163 \\
(0.393)\end{array}$ & $\begin{array}{c}2.023 \\
(0.325) \mathrm{a}\end{array}$ & $\begin{array}{c}1.819 \\
(0.335) \mathrm{a}\end{array}$ \\
\hline $\begin{array}{c}\text { Total BMD } \\
(\mathrm{g} / \mathrm{cm} 2)\end{array}$ & $\begin{array}{c}1.008 \\
(0.109)\end{array}$ & $\begin{array}{c}1.061 \\
(0.106)\end{array}$ & $\begin{array}{c}1.012 \\
(0.105)\end{array}$ & $\begin{array}{c}0.946 \\
(0.098) \mathrm{a}\end{array}$ \\
\hline $\begin{array}{c}\text { Total BMD } \\
\text { T-scoreb }\end{array}$ & $-1.34(1.15)$ & $-0.79(1.12)$ & $-1.30(1.11)$ & $\begin{array}{c}-2.00(1.04) \\
\mathrm{a}\end{array}$ \\
\hline
\end{tabular}

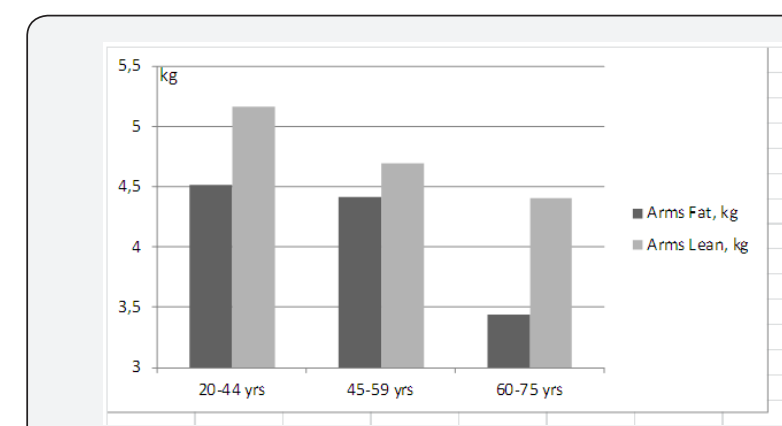

Figure 1A: Arms.

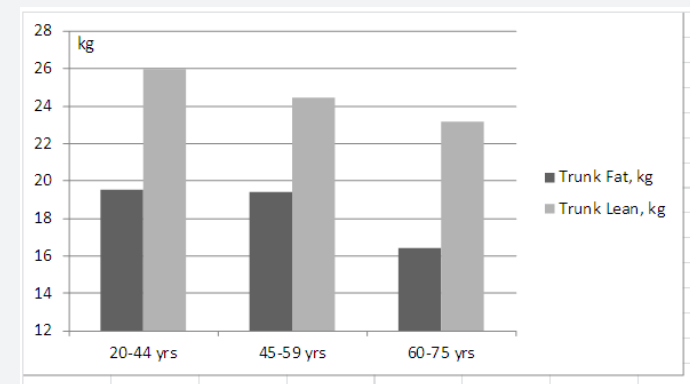

Figure 1B: Legs.

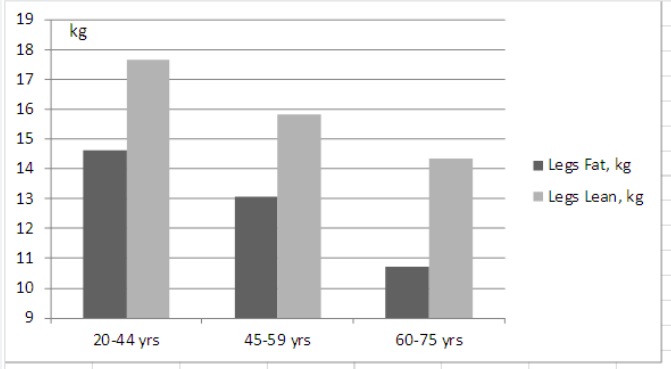

Figure 1C: Trunk.

Figure 1: Age-adjusted means of fat and lean mass $(\mathrm{kg})$ in three different body regions - arms, legs and trunk.

Figures 1a-1c show the age-adjusted means of FM and LM in three different body regions- arms, legs and the trunk. In the arms, LM shows a greater difference between the ages of 2044 and 45-59 years than between the ages of 45-59 and 60-75 years, while the difference in FM is greater between the ages of 45-59 and 60-75 years (Figure 1a). The same tendency of FM, declining more steeply in older ages, can be seen for the trunk (Figure 1c), while in the legs, FM and LM show an almost parallel decline with aging (Figure $1 \mathrm{~b}$ ). The mean percentages of total and regional FM are displayed on Figure 2. These are highest in the middle-aged group (45-59 years). 


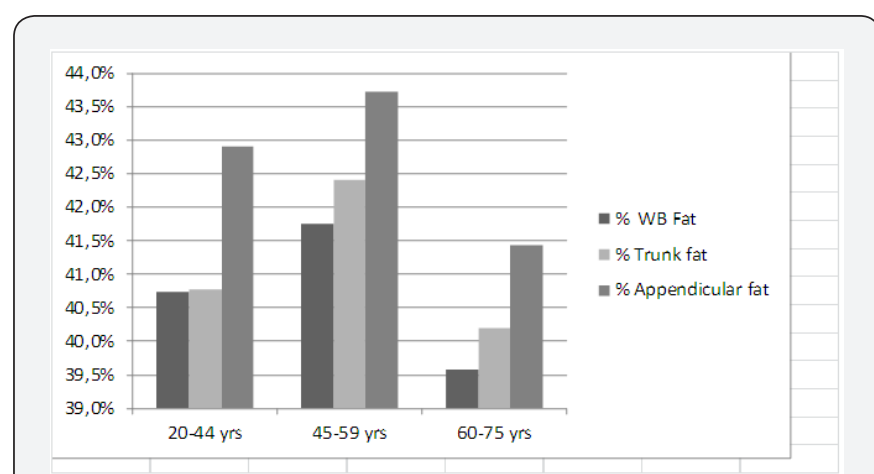

Figure 2:Mean percentages(\%) of total and regional (arms, legs, trunk) FM.

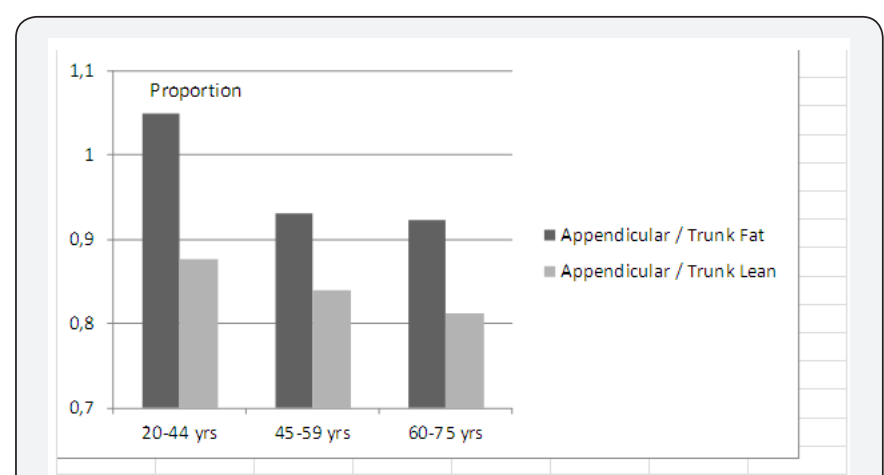

Figure 3:Ratio of appendicular to trunk fat mass and trunk lean mass, respectively, in the different age groups.

Figure 3 shows the ratio of appendicular to trunk fat mass and trunk lean mass, respectively, in the different age groups. The proportion of appendicular fat and lean mass is decreasing steadily with aging, showing a more centripetal body mass predisposition. The most marked redistribution can be seen between the ages of 20-44 and 45-59 years, involving the fat mass.

\section{Discussion}

This is the first study in our country that reports DXA-derived estimates of whole and regional body composition analysis. Total BMC and BMD of the studied women were consistently lower than the Hologic and NHANES 1999-2004 reference databases and were lower with advancing age. A similar age-related difference was seen in regional LM and FM. FM decreased at different rates in the trunk, legs and arms and predominantly at older ages, whereas LM followed an almost linear pattern of decline with aging. This resulted in \% FM that was highest in the middle-aged group (45-59 years). Trunk fat remained almost similar in the 20-44 and 45-59-year aged groups, which led to a significant difference in the appendicular/trunk fat ratio. We made an attempt to explain these findings with the influence of at least three factors: 1 / increase of chronological age; 2/ perimenopausal and postmenopausal transition, since all women aged under 45 years were premenopausal, while the elderly were postmenopausal; 3/ decreasing BMI in the elderly age group that results in smaller body proportions affecting the FM and LM and their ratios in the trunk and limbs. In brief, our results show that LM and FM do not follow the same pattern of age-related differences in the various body regions.

A number of studies have published body composition estimates coming from Asia, Europe and North America [1120]. Few among them have examined the relationships of FM and LM with BMD $[13,14,16]$, while others have suggested local reference values $[11,12,15,17,18,20]$. Comparing our data to these of a Spanish study, we found a major difference concerning the changes in total FM and \% FM with aging [20]. While the Spanish women showed a consistent increase in total body FM and \% FM throughout life, our data indicate a steady decline of absolute FM and a peak of \% FM around the perimenopausal and early postmenopausal ages (45-59 years). However, data of both studies are similar for the total body LM, which is decreasing with advancing age. A similar trend for increasing the total body FM and \% FM throughout life was observed in Italian subjects $[18,19]$. On the contrary, a study in healthy Brazilian women registered a bimodal distribution of body fat- increasing until 50-59, with a slight subsequent decrease [17]. The lowest values of $\mathrm{FM}$ and \%FM in the elderly group of our study population might be explained by the decreasing BMI-starting at a mean of $36.0 \mathrm{~kg} / \mathrm{m}^{2}$ in the youngest age group and reaching $30.4 \mathrm{~kg} / \mathrm{m}^{2}$ in the oldest one. This discrepancy underlines the need for BMI adjusted reference values. Such BMI-adjusted reference values have already been published for other populations [11], but our study group was under powered for this kind of analysis.

Our data are different from the published body composition indices in a 20-to-80-year-old healthy Italian population [18]. In this particular study, trunk FM values were higher in older subjects, while the leg FM was similar in women at different ages. In another publication, based on the same data set, women's arm FM increased with aging, their arm fat-free mass remained stable, while decreasing in their legs [19]. These studies, along with our findings, may raise the hypothesis for the different weight-bearing roles of the upper and lower limbs, resulting in differential FM and LM changes with aging.

We also made an attempt to compare our data with the NHANES 1999-2004 reference population, as published by the ISCD [22]. Almost all body composition indices were higher in the studied women, showing the presence of a systematic difference. It may be explained by genetic and ethnic factors, but also by the predominantly high BMI in our study population. The impact of race-ethnicity can easily be seen in the publications based on the 1999-2004 NHANES data [21]. Most of our participants had over weight or obesity. As a consequence, our study underlines the need for national-based body composition data from subjects with different levels of BMI, reflecting the nation-specific levels of over weight and obesity. 
Our study has a number of limitations. First, the number of participants is rather modest, which prevented us from separate analyses based on BMI.Second, we were unable to study separately the contribution of menopause to changes in body composition, since the younger age group included premenopausal, while the middle-aged and elderly group- postmenopausal women only. In a study assessing the relative contribution of aging and menopause to changes in LM and FM in segmental regions, the decrease in LM was found to be more menopause-related, while the shift toward upper body fat distribution - more age-related $[26,27]$. Third, this is a post hoc analysis in women referred for DXA for a variety of indications. Our data cannot be generalized to the whole female population. And fourth, the study design is cross-sectional, allowing rough estimates of real age-related changes in body composition only. Until now, there are no studies reporting longitudinal body composition changes in a given population for longer time periods (e.g. >10yrs).

One of the major strengths of our body composition study is that it is the first DXA-based study in our country. DXA is a non-expensive and very precise method for studying the body composition, being critically validated in a variety of studies $[6,7,28,29]$. The mean difference between the body weight values coming from DXA and from the digital scale balance in our data set was less than $0.5 \mathrm{~kg}$, meaning that DXA has quite accurately estimated the real weight.

\section{Conclusion}

Aging has a more pronounced effect on fat than lean mass. The reductions of fat and lean mass are not parallel in the different body regions. Nationally representative data on body composition adjusted to BMI are needed.

\section{Acknowledgment}

The author would like to thank Assoc. Prof. Dr. Zhivka BonevaAsiova (Head of the Endocrine Unit, MVR Institute- Central Hospital, Sofia) and the DXA technologist Darina Antonova from the same Endocrine Unit for their technical support and devotion to this study.

\section{Conflicts of Interest Statement}

The author declares no direct or indirect conflicts of interest related to this study.

This research did not receive any specific grant from funding agencies in the public, commercial, or not-for-profit sectors. The author has received speaker honoraria from a number of pharmaceutical companies such as Amgen Inc., F. Hoffmann-La Roche Ltd., Eli Lilly and Company, Novo Nordisk, Sanofi-Aventis, Laboratoires Servier, Novartis AG, Merck-Sharpe and Dohme, Merck GMBH, InoTech and others.

\section{References}

1. Villareal DT, Apovian CM, Kushner RF, Klein S, American Society for Nutrition (2005) Obesity in older adults: technical review and position statement of the American Society for Nutrition and NAASO, The Obesity Society. Am J Clin Nutr 82(5): 923-934.

2. Borissova AM, Shinkov AD, Vlahov JD, Dakovska LN, Todorov TC (2015) Survey on the prevalence of obesity in Bulgarian population in 2012 year. J Endocrinologia 20: 82-92.

3. Rotella CM, Dicembrini I (2015) Measurement of body composition as a surrogate evaluation of energy balance in obese patients. World J Methodol 5(1): 1-9.

4. Graf CE, Karsegard VL, Spoerri A, Makhlouf AM, Ho S, et al. (2015) Body composition and all-cause mortality in subjects older than $65 \mathrm{y}$. Am J Clin Nutr 101(4): 760-767.

5. Falsarella GR, Gasparotto LP, Barcelos CC, Coimbra IB, Moretto MC, et al. (2015) Body composition as a frailty marker for the elderly community. Clin Interv Aging 10: 1661-1666.

6. Van Loan MD, Mayclin PL (1992) Body composition assessment: dualenergy X-ray absorptiometry (DEXA) compared to reference methods. Eur J Clin Nutr 46(2): 125-130.

7. Van Loan MD (1998) Is dual-energy X-ray absorptiometry ready for prime time in the clinical evaluation of body composition. Am J Clin Nutr 68(6): 1155-1156.

8. Kendler DL, Borges JLC, Fielding RA, Itabashi A, Krueger D, et al. (2013) The Official Positions of the International Society for Clinical Densitometry: indications of use and reporting of DXA for body composition. J Clin Densitom 16(4): 496-507.

9. Müller MJ, Geisler C, Pourhassan M, Glüer CC, Bosy-Westphal A (2014) Assessment and definition of lean body mass deficiency in the elderly. Eur J Clin Nutr 68(11): 1220-1227.

10. Coin A, Sarti S, Ruggiero E, Giannini S, Pedrazzoni M, et al. (2013) Prevalence of sarcopenia based on different diagnostic criteria using DEXA and appendicular skeletal muscle mass reference values in an Italian population aged 20 to 80. J Am Med Dir Assoc 14(7): 507-512.

11. US Department of Health and Human Services (2010) Body composition data for individuals 8 years of age and older: U.S. Population 19992004. Vital and Health Statistics 250(series 11): 95.

12. Marwaha RK, Garg MK, Bhadra K, Mithal A, Tandon N (2014) Assessment of lean (muscle) mass and its distribution by dual energy X-ray absorptiometry in healthy Indian females. Arch Osteoporos 9: 186.

13. Marwaha RK, Garg MK, Tandon N, Mehan N, Sastry A, et al. (2013) Relationship of body fat and its distribution with bone mineral density in Indian population. J Clin Densitom16(3): 353-359.

14. Zhang J, Jin Y, Xu S, Zheng J, Zhang Q et al. (2015) Associations of fat mass and fat distribution with bone mineral density in Chinese obese population. J Clin Densitom18(1): 44-49.

15. Cheng Q Zhu X, Zhang X, Li H, Du Y, et al. (2014) A cross-sectional study of loss of muscle mass corresponding to sarcopenia in healthy Chinese men and women: reference values, prevalence, and association with bone mass. J Bone Miner Metab 32(1): 78-88.

16. Lee K (2013) Regional percent fat and bone mineral density in Korean adolescents: the Fourth Korea National Health and Nutrition Examination Survey (KNHANES IV-3), 2009. Asia Pac J Clin Nutr 22(1): 69-73.

17. Sousa MD, Pinheiro MM, Szejnfeld VL, Castro CH (2013) Body composition parameters in healthy Brazilian women differ from white, black, and Hispanic American women reference range. J Clin Densitom 16(3): 360-367.

18. Coin A, Ruggiero E, Giannini S, Pedrazzoni M, Minisola S, et al. (2012) Trunk and lower limb fat mass evaluated by dual-energy X-ray 
absorptiometry in a 20- to 80 -year-old healthy Italian population. Ann Nutr Metab 61(12): 151-159.

19. Coin A, Giannini S, Minicuci N, Rinaldi G, Pedrazzoni M, et al. (2012) Limb fat-free mass and fat mass reference values by dual-energy X-ray absorptiometry (DEXA) in a 20-80 year-old Italian population. Clin Nutr 31(4): 506-511.

20. Henche SA, Torres RR, Pellico LG (2008) An evaluation of patterns of change in total and regional body fat mass in healthy Spanish subjects using dual-energy X-ray absorptiometry (DXA). Eur J Clin Nutr 62(12): 1440-1448.

21. Heo M, Faith MS, Pietrobelli A, Heymsfield SB (2012) Percentage of body fat cutoffs by sex, age, and race-ethnicity in the US adult population from NHANES 1999-2004. Am J Clin Nutr 95(3): 594-602.

22. Petak S, Barbu CG, Yu EW, Fielding R, Mulligan K, Sabowitz B, et al. (2013) The Official Positions of the International Society for Clinical Densitometry: body composition analysis reporting. J Clin Densitom16(4): 508-519.

23. Boneva-AZ, Boyanov MA (2008) Body composition analysis by leg-toleg bioelectrical impedance and dual-energy X-ray absorptiometry in non-obese and obese individuals. Diab Obes Metab 10(11): 1012-1018.

24. Hangartner TN, Warner S, Braillon P, Jankowski L, Shepherd J (2013) The Official Positions of the International Society for Clinical

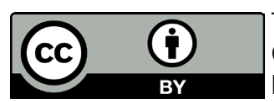

Densitometry: acquisition of dual-energy X-ray absorptiometry body composition and considerations regarding analysis and repeatability of measures. J Clin Densitom16(4): 520-536.

25. Glüer C, Blake G, Lu Y, Blunt BA, Jergas M, Genant HK (1995) Accurate assessment of precision errors: How to measure the reproducibility of bone densitometry techniques. Osteoporos Int 5(4): 262-270.

26. Cruz-JAJ, Baeyens JP, Bauer JM, Boirie Y, Cederholm T, et al. (2010) Sarcopenia: European consensus on definition and diagnosis: Report of the European Working Group on Sarcopenia in Older People. Age Ageing 39(4): 412-423.

27. Douchi T, Yamamoto S, Yoshimitsu N, Andoh T, Matsuo T, Nagata Y (2002) Relative contribution of aging and menopause to changes in lean and fat mass in segmental regions. Maturitas 42(4): 301-306.

28. La Forgia J, Dollman J, Dale MJ, Withers RT, Hill AM (2009) Validation of DXA body composition estimates in obese men and women. Obesity (Silver Spring) 17(4): 821-826.

29. Lohman M, Tallroth K, Kettunen JA, Marttinen MT (2009) Reproducibility of dual-energy x-ray absorptiometry total and regional body composition measurements using different scanning positions and definitions of regions. Metabolism 58(11): 1663-1668.

\section{Your next submission with Juniper Publishers will reach you the below assets}

- Quality Editorial service

- Swift Peer Review

- Reprints availability

- E-prints Service

- Manuscript Podcast for convenient understanding

- Global attainment for your research

- Manuscript accessibility in different formats

(Pdf, E-pub, Full Text, Audio)

- Unceasing customer service

Track the below URL for one-step submission https://juniperpublishers.com/online-submission.php 